Behavior and Social Issues, Volume 6, No. 1, Spring 1996

\title{
REMINISCENCES: FRED S. KELLER: AN APPRECIATION
}

\author{
Donald A. Cook \\ Cambridge Center for Behavioral Studies
}

\begin{abstract}
When I began attending Fred Keller's lectures in psychology in 1946, there was an immediate change in my behavior. Commuting to Columbia from a Long Island town, I had been catching the 7:51 or even the 8:05 to make my 9 A.M. classes. (I would often reach the campus late, and would make this an excuse to go and read poetry.) But now that Keller was lecturing the early class, I began boarding the $7: 31$. My friends and parents marveled, and I did, too.

How great those lectures were! They were quiet, but steadily on target: You knew you were learning the limits of what was known in psychology-no matter what the epoch of the work, no matter what the "school" of the researcher. Abstract ideas and grand theories had their place, but they were cut down to size and interlarded with tables of data, or a sketch of a monkey discriminating tones while listening through earphones, or a graph of the resulting stimulus generalization. The lectures were thoughtful, with each point well-supported, and conceptually worked out, with touches of humor but no straying from the path-what do we really know about behavior? Respect was given to good data regardless of source, or the questionable interpretations made by others-even the author of the data!

In those days, there were mimeographed notes but no textbook yet. These terse notes were incredibly valuable; I still have my set. Studying for a midterm, I would stand on the railway platform while changing trains at Jamaica: "As generalization increases, latency decreases." How could I remember this inverse relationship? Ah: Speed! If things are similar, you respond faster. That was the key. And so in my own thinking there were forged the foundations needed to understand this field of study.
\end{abstract}

\section{Lectures and Textbook}

For me a pervading irony resides in the fact that this man whose "Personalized System of Instruction" undermined the salience of lectures in university life, gave those memorable lectures. When thoughtless enthusiasts of PSI say breathlessly, "No boring lectures in this method of instruction!" I sometimes ask, "How about non-boring lectures-are they also eliminated?" The question is usually not appreciated. (As for non-thoughtless enthusiasts-well, that is another story).

AUTHOR'S NOTE:

Please address all correspondence to: Donald A. Cook, 36 Burroughs St., Jamaica Plain, MA 02130. 


\section{COOK}

Keller was among the best of Columbia's great teachers. He was, at that time, (having been born on January 2, 1899, in Rural Grove, New York); he seemed at the height of his powers, and it was the year he became an Associate Professor. It was a height at which he would remain for a long time.

The undergraduate psychology student of that time moved from the introduction provided by Keller, into the rigors of experimental design (and associated conceptual analysis) with Nat Schoenfeld, an examination of human dysfunction in Ralph Hefferline's course in abnormal psychology, then as a senior was able to take seminars in emotion and verbal behavior in which all three of these remarkable teachers came together.

Date of First Citation of Well-known Psychologists

in Principles of Psychology by Keller and Schoenfeld

\begin{tabular}{|c|c|}
\hline Year & Citations \\
\hline 1949-50 & Bersh, Dinsmoor, Reich, Zipf \\
\hline $1947-48$ & Harlow, Sheffield \\
\hline 1945-46 & Hebb, Masserman \\
\hline 1943-44 & Bitterman, Estes \\
\hline 1941-42 & Miller, Muenzinger, Sears \\
\hline 1939-40 & Brogden, Mowrer, Razran \\
\hline 1937-38 & Hovland, Tolman, Woodworth \\
\hline 1935-36 & Scholsberg, Spence \\
\hline \multicolumn{2}{|l|}{ 1933-34 } \\
\hline 1931-32 & Luria, Smoke \\
\hline 1929-30 & Piaget, Skinner \\
\hline 1927-28 & Cannon, Stone \\
\hline 1925-56 & Kohler, Tsai \\
\hline 1923-24 & Allport, Kantor, McDougall, Wang, Warden \\
\hline 1921-22 & Guthrie, Richter \\
\hline 1919-20 & Hull, Hunter \\
\hline 1917-18 & Pavlov \\
\hline 1915-16 & Lashley, Watson \\
\hline \multicolumn{2}{|l|}{ 1913-14 } \\
\hline \multicolumn{2}{|l|}{ 1911-12 } \\
\hline 1909-10 & Kent-Rosanoff, Yerkes \\
\hline $1907-08$ & Titchener \\
\hline 1905-06 & Henmon \\
\hline 1903-04 & Tarde \\
\hline 1901-02 & Scott, Small \\
\hline 1899-00 & Bryan, Harter \\
\hline $1897-98$ & Thorndike \\
\hline 1890 & James \\
\hline 1885 & Ebbinghaus, Merkel \\
\hline 1884 & James \\
\hline 1883 & Galton \\
\hline 1855 & Spencer \\
\hline 1651 & Hobbes \\
\hline
\end{tabular}

By the time I began graduate school in 1948, the undergraduate laboratory had begun running on a large scale and Fred had co-authored a textbook. I was one of 
those early lab assistants, and so saw the flowering of the golden age, when the dissertations on discrimination (Fred Frick), secondary reinforcement (Jim Dinsmoor, Joe Notterman, Phil Bersh), response variability (Joa Antonitis), avoidance (Murray Sidman) and others, were staking out the parameters and the families of curves which sustained the functions demonstrated in the trail-blazing work of B. F. Skinner.

The textbook Principles of Psychology by Fred S. Keller and W. N. Schoenfeld was published in 1950. For more than ten years thereafter, students of this text whose teachers were the same two authors, those who experienced the Columbia laboratory-based curriculum, made extensive contributions to the research in the experimental analysis of behavior, and in turn became the major teachers of many others entering the field.

Often described as a presentation of the chief concepts and experimental data from the work of B. F. Skinner, the book also describes many experimental studies from a vast range of sources, ranging over some 100 years of major contributions to the study of behavior.

To understand such a variety of studies requires the interpretation of many different types of independent variable, and a sense of the connections between many measures of behavior in addition to the rates and slopes of cumulative records. To assemble such a diverse mass of relationships into a coherent account, demands the rational reconstruction of investigations in psychology which may have been carried out under various points of view, some no longer systematically viable. The textbook of Keller and Schoenfeld is a masterpiece of this kind of analysis and synthesis.

\section{Early Years}

Known to fewer people than the accomplishments of the Columbia course, book, and laboratory, are the earlier years of Fred Keller, which preceded this famous epoch. Critical to the story are his years as a Western Union telegraphic delivery boy and a code operator using American Morse Code. In those days, this now moribund means of communication was an avenue of escape from the confines of small-town life; one was in touch with a wider world, and the harbinger (on a bicycle) of exciting news — be it good or bad-brought to one's neighbors. After earning a B.A. at Tufts University in 1926, Fred followed the advice of a mentor who, upon hearing of his interest in the field of advertising, suggested graduate study in psychology.

Where else might one already in the Boston area go, but to Harvard? In the course of acquiring an MA in 1928 and a Ph.D. in 1931, this chapter provided the setting for Fred's friendship with fellow student B. F. Skinner. In the lab and over beer and skittles at Jacob Wirth's (still there!), they shaped out the behaviorist in each other. (Keller's dissertation was on W. S. Hunter's double-alternation problem: How could a rat know which way to turn this time in the temporal maze, when the only relevant data was that the correct turn was the opposite of the turn for the last time?)

During Keller's years as an instructor in psychology (Tufts: 1926-28; Colgate: 1931-38; Columbia: 1938-41), he experimented with various blends of the usual eclectic coverage, and with a systematic approach based upon Skinner's evolving formulations. The year 1938 saw the appearance of two great books: Skinner's The 


\section{COOK}

Behavior of Organisms and R. S. Woodworth's Experimental Psychology. The attempt to utilize the system of the first, to re-organize the breadth and scope of the second-these were the challenges of his years as an Assistant Professor at Columbia (1941-46).

While working out his integration of systematic principles with the wide scope of the subject, Keller encountered an opportunity to test the application of reinforcement theory to an important practical problem.

Morse Code Research

When the United States entered World War II in 1941, the Army signal Corps trained recruits in sending and receiving Morse Code by the traditional approach: Memorizing the alphabetic equivalents of the sequences of dots and dashes of the Code from visual lists of these signals. The trainee would examine these lists and vocalize the signals to himself: "Dit-dah" is A, "Dah- dit-dit-dit" is B, etc.

Keller could now review his experience as a code learner and operator from the standpoint of systematic theory in psychology. He recast the problem of code learning as one to be directly addressed by Skinner's basic paradigm for an operant discrimination. Out of this came the "code-voice" method, which Keller referred to as "a modification of the well-known procedures of 'paired associates' and 'regular reinforcement.'" Trainees would directly encounter the actual auditory signals, and be asked to write a character in response to each signal as it appeared. The training environment was arranged to permit immediate confirmation or disconfirmation of each such response, by a human voice speaking through the same earphones that carried the signals, in the short time interval separating signals. Trainees responded to each signal by writing a character on a special "Code Practice Sheet" These guesses were written in the upper box in the row. A few seconds after each signal, the instructor named the correct response by voicing its phonetic equivalent ("Able," "Baker," "Charlie," etc.). If the trainee's response was correct, the identification confirmed that response. If it had been incorrect, the trainee wrote the correct character in a second box underneath the guess. The entire procedure of the "Code-Voice" Method was an early and very specific application of reinforcement theory.

The method was tested at Columbia (the first joint writings of Keller and Schoenfeld are found in these studies), then evaluated and implemented at Camp Crowder, Missouri, the locus of training for the Army Signal Corps. By 1944, the code-voice method was shown to be far superior to methods in use during the early stages of World War II.

In 1955 a retrospective survey stated that "the code-voice method...developed during World War II.. is the most effective method yet developed for initial training in code reception..."

Apart from this triumph of applied science, important lessons of another kind were learned at Camp Crowder-lessons worth remembering as we continue efforts to improve educational practices by the use of behavioral principles.

Challenges of Innovation 
Listen to Fred Keller:

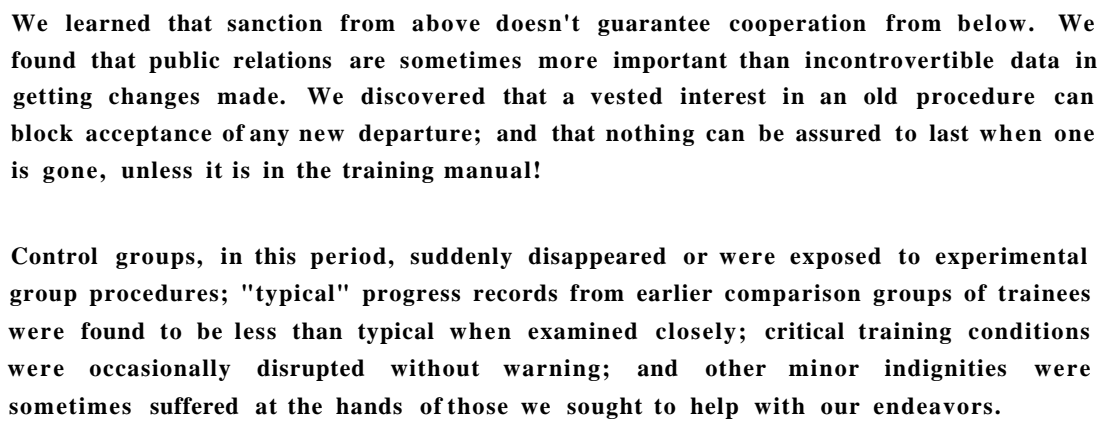

Control groups, in this period, suddenly disappeared or were exposed to experimental group procedures; "typical" progress records from earlier comparison groups of trainees were found to be less than typical when examined closely; critical training conditions were occasionally disrupted without warning; and other minor indignities were sometimes suffered at the hands of those we sought to help with our endeavors.

These remarks have the ring of prophesy when viewed in the light of later attempts to improve educational practices by the application of sound behavioral principles.

\section{Rewriting the Canon}

Some of the research themes continued to interest Fred and his students, after the war's end, in the quieter environment of Columbia. Under a contract with the Air Force Human Factors Operations Research Laboratories, new studies were carried out which suggested that the famous plateaus said by Bryan and Harter, in their classic papers of 1897 and 1899, to be an essential part of progress in code learning, were neither essential nor typical. These plateaus were supposedly characteristic of meaningful text messages, and represented a period of transition between attending to letters and to "words- as-a-whole." Since the beginning of the century, the notion of a hierarchy of language habits lent plausibility to a theory only sketchily supported by data. These "plateau curves" at one time could be found in all the major textbooks of psychology.

But by 1955 , a survey of the Columbia and related work, concluded that "...plateaus are probably not intrinsic to the code learning task, but rather the result of factors whose operation can either be prevented or cured by intelligent instructional procedures."

In 1957, Keller gave his presidential address before the Eastern Psychological Association. By that time, the title of the address, "The Phantom Plateau," was indicative not merely of Keller's own view, but of all workers in the field of code learning. The impact extended beyond the field of code to all learning in general-as "plateaus" began to disappear from the paradigms of "complex human learning."

By 1959, we find Albert Kurtz saying, in a review produced under contract for the Office of Naval Research, "In contrast with Bryan and Harter's classic study of 60 years ago, modern studies usually find learning curves with such slight negative acceleration that they do not differ markedly from straight lines. Plateaus are not typical" (p. 45).

The plateaus, once a staple of basic texts such as those of Woodworth, Boring, Langfeld and Weld, or Munn, have vanished. Today's students hardly know that they 


\section{COOK}

were once there, as they debate the use of semi-logarithmic charts of response rate. Since code itself has all but vanished, it might seem of little interest to review this work. But I say unto you: Look not for code, but instead look about for claims that other types of learning must be slow, and held back by periods of digestion by unknown internal processes-and you will not have far to look!

My dissertation was a contribution to this research program, but its lesson for me was generic in another sense. Without a conscious plan, my graduate career had provided a transition from the well-controlled experiments with animals-first as a student, then as a laboratory assistant-to an application in human learning. With code material transmitted at controlled speeds through a naval training device, and with my voice providing the feedback though the same microphones, I saw 17 out of 17 learners acquire code reception skills more quickly than hitherto reported in the official literature. For me, the issue of the "generality of reinforcement methods across species" was thus nipped in the bud. Problems arose not because one was changing species, but when one abandoned the careful conditions which could be maintained in the laboratory. Given the data I collected and plotted daily, extrapolation to humans required no leap of faith.

\section{The Culture of the Laboratory}

The Columbia psychology department was scattered over four floors of Schermerhorn Extension, and its heart was the undergraduate laboratory and nearby vivarium on the second floor. The lab room contained 12 cubicles holding two students apiece and was filled every day by students from the introductory course. Each cubicle contained a table which held, in addition to the rat of the hour (brought from and returned to the vivarium), a lever, which slid in and out of the animal's cage, and whose depression actuated a microswitch, a cumulative response recorder on a revolving drum, a four-channel recorder with styli marking a slow-moving waxed tape, outlets for light and sound stimuli, a pellet dispenser actuated by electromagnet, and a stimulus control box whose circuitry controlled lights, tones, and shocks.

Despite some degree of automation, we as experimenters could not walk away from our experiments. We implemented interval schedules by watching the second hand of clocks on the wall of the darkened lab, and we made pencil marks to do the counting required in ratio schedules. The food magazine was actuated by a switch, but we closed that switch by hand.

Murray Sidman feels that this transitional epoch was not without its virtues: "At that time, the whole thing was much more an interaction between us and the animal, and is perhaps responsible for a feeling we have about experimentation that those who came later and simply observed equipment interacting with the animal could not appreciate." (M. Sidman, personal communication, 1996)

The graduate assistants who ran these labs supervised at least 24 students each week as they carried out experiments upon 12 rats, in a sequence progressing from conditioning and extinction to schedules, discrimination, the shaping of new responses, chaining, escape conditioning, and more complex variations late in the course. In addition to weekly assistants' meetings, where lab procedures were 


\section{FRED S. KELLER}

established and typical (and atypical!) results compiled, daily lunches in the vivarium (which Mike Reardon kept spotless and which contained a small gas range and a refrigerator full of hamburgers) gave us a steady setting in which a culture was born, nourished, and sustained. To eat amongst the animals-not only the hundreds of rats but a handful of C. J. Warden's monkeys and cats (lest we forget the problems of species comparison)—seemed appropriate.

The main outcome produced by a couple of years of this, was, I believe, a sustained expectation that behavior was orderly, that reinforcement principles could be verified, and that the study of operant behavior applied to the individual organism. All the experiments worked, and worked with all animals, even when these animals were in the hands of varied students. Slowly we stabilized the system for export.

The ideas developed in the labs were extended, and some became famous demonstrations. Thom Verhave built a special apparatus in which a rat-Thorn called him "Bozo"-climbed ladders, pulled strings, swung in a basket, and rode in an elevator; all in the right order, and all for a 0.10 gram of chow. This was accomplished by establishing links in the chain backwards-an idea condemned as pointless by the traditional comparative psychologist C. J. Warden, who "knew" that a rat's limit (established in the Warner-Warden maze) fell far below this fantastic achievement. He refused to enter Thorn's office to see this demonstration, and Thom gradually moved the apparatus-animal running in it-out into the halls of Schermerhorn. One day Fred Keller took me aside and said, "Could you please prevail upon Thom to lay off with Bozo: poor old C. J. can't get down the hall to the bathroom, and is now staggering upstairs to the third floor to handle nature's call."

A major challenge was simply to get some demonstrations into classrooms outside of Schermerhorn. For Keller's evening classes in General Studies, I built a small portable lab system, and learned how to adapt rats to the emotional trauma caused by being wheeled in a metal cart across bumpy cobblestones between buildings. The answer was simple: Wheel them across the campus, while running the experiment, every day for several days beforehand!

During vivarium lunches we would sometimes dream of bringing the course to the whole world. We envisaged a traveling van, which would carry staff, animals, lab, and equipment, from town to town, like a circus. "I think perhaps," Keller would say, "that most people across America would like a chance to do an experiment."

Nearby Barnard College, across Broadway, in steady search of young instructors, was willing to build its own vivarium, and enrolled students with certain attractions. Bill Cumming, Gil Sherman, Bill Stebbins, George Gurevitch, Ed Cobb, Tom Perrera, myself, and others, were among the Columbia students who brought the Keller-Schoenfeld text and accompanying lab system across the street. Thom Verhave's amazing chain became an annual project for several generations of Barnard students—and their rats, whose name now mutated from "Bozo" to "Barnabus."

Under the right circumstances, the dissemination transcended distance. Autonomous centers which taught a psychology system based upon the Keller and Schoenfeld text, together with the basic lab course, were established over the years, beginning with Tom Reese at Mount Holyoke (where his student became his wife and 
directed a long-lived program), and others.

When Jim Dinsmoor went to Indiana, he inherited a lab course as it had been established by Skinner during his years in Bloomington. Dissemination began to take more complex paths. (J. Dinsmoor, personal communication, 1996) Dick Malott, who first experienced the lab under Jim Dinsmoor's tutelage at Indiana, then came to Columbia for his Ph.D. In turn, he helped develop and expand the undergraduate lab offerings at his subsequent teaching positions at Denison, and then at Western Michigan, where his upper-class lab course enrolls 200 students each year. (R. Malott, personal communication, 1996)

Tony Nevin went from Columbia to Swarthmore and established a lab course there. Then he returned to Columbia and collaborated with Bill Cumming in the evolution of the course (Keller and Schoenfeld having both left), then departed again, this time to the University of New Hampshire, to launch yet another incarnation of the laboratory.

At Columbia, the undergraduate course established in the 40 's is still going strong, and still serves to fulfill an undergraduate requirement in a laboratory science. This last fact-once personalities and lore have faded into oblivion-may remain as the durable event in a slowly evolving intellectual culture. A recent report from Herbert Terrace (presently a Columbia professor) tells of the upgrading of the laboratory to incorporate computer software control of the experimental procedures. Time marches on. (H. Terrace, personal communication, 1996)

Graduates of this system continue to be struck by the degree to which, though spanning decades, they can talk to each other as it from a large family. They share not only memory and vocabulary, but also certain values-a belief that the behavior of organisms is orderly, that reinforcement is powerful though not always "rational" ways, that punishment has complex and uncertain effects, and that invisible events or entities as either explanatory or moral agents are to be viewed with skepticism.

\section{A New Career After Retirement}

When Fred became a Full Professor in 1960, he was 61 years old. The moment of his official retirement, in 1964, would be for many the beginning of a period of the cultivation of quieter gardens. A distinguished teaching career, a fine book, research achievements in the animal and human laboratory, the presidency of the Eastern Psychological Association, and the Truman Award (in 1948, in honor of his Morse Code work) — was that not a life of sufficient accomplishment? But for Fred it was the inception of a new 30 year chapter of innovation and increased impact worthy of a second lifetime.

In the period from 1960-64, Fred made two trips to Brazil-the first of many to follow in the years to come. In his 1964 trip, Fred set up Psychology, with his new course, at the new University of Brasilia. Between the first and second trips he designed, and during the second trip he implemented the teaching method now known as the Personalized System of Instruction. Foremost among the Columbia group who evolved PSI was J. Gilmour Sherman. Sherman accompanied Keller to Brazil, served as a faculty member, and shares the honors as co-developer of the PSI method. Keller's (1968) paper, "Good-bye, Teacher," has become one of the 
best-known papers on the application of behavioral principles to instruction. Like its behavioral cousins, programmed instruction and precision teaching, PSI has a powerful track record of yielding notable instructional gains when implemented properly. But also like them, PSI is controversial, puts strains on the undisturbed complacency of most educational practices, and sometimes-especially when the threat of improved instruction is brandished in a combative and arrogant manner-induces repressive countermeasures in educational institutions.

Of Keller's three most notable and sustained activities (the Morse code research, the laboratory course, and PSI), two of them address instructional arrangements in which "the teacher" cannot function as a point from which course essentials are "broadcast" to the student. A lecturer cannot very effectively emit Morse code signals, nor can he serve as the sole or central event in a course whose students speak Portuguese when the teacher lectures in English. In the laboratory course a more mixed economy can prevail, though even here the interaction between student and experimental subject becomes critical, and may, with salutary effect, rival the impact of the lecturer. A full armamentarium of instructional practices must someday provide appropriate analyses of all these variations. Among them, the configurations launched by Fred Keller will be archetypical.

In the years following upon the inception of PSI in Brazil, Keller taught at Arizona State University in Tempe, served at the Institute for Behavioral Research, and taught at the University of Western Michigan. From 1974-76, he held a position at Georgetown University while working with the Center for Personalized Instruction which had been established there. And from 1980 until his death in Chapel Hill in February, he held an adjunct research position at the University of North Carolina.

During this period, many official awards came his way: From the American Psychological Association for contributions to teaching (1974) and to psychology (1976), and One from Brazil's Ministry of Labor (1979).

\section{Fred Keller the Man}

Throughout all, Fred Keller remained the man who steadily showed up at meetings where his students described their research, presented their papers, and held their symposia. He tracked them all, and would often refer to their latest work in his own talks. To those who might wonder about what subtle contingencies of reinforcement were employed by this man who had such powerful effects upon so many of us, the answer seems simple: If you showed up to give your own paper, there he would be.

Very often he would be accompanied by Frances, his wife. Her centrality in his peripatetic life and career was clear to all. Frances remembers vividly the earlier days in which, gatherings were not yet weighed by fame and dignity, but rather marked by unceasing talk, the pleasures of drink and tobacco, and lasted into hours perhaps imprudently late.

On February 2, 1996, with his family present, Fred S. Keller passed away at home in Chapel Hill. My own reactions to this event tell me that, even though his loss at this point is no surprise, many will strongly miss this fine teacher and leader. This mixture of appreciation and sadness has been exchanged numberless times in 


\section{COOK}

these last few weeks.

From the stream of exchanges carried out by e-mail, I would like to select a statement of William J. McGill, who had been a fellow faculty member at Columbia, and later president of that same university: "Fred was very special. His nobility of spirit and dedication to his students were remarkable even by the standards of an earlier, more humane era. These things are now almost entirely absent from university life." (W.J. McGill, personal communication, 1996)

Thanks to these qualities, Fred's influence upon his many students was extremely positive. Thanks to his long and active life, it was also strong, and will continue to be so. Though he will be missed, his teaching and its quality help equip us who were his students to be-or try to be-just a bit like him, with our students and with others. It is truly moving to have known him, and in that sense to continue to know him.

A memorial service is scheduled for Monday, April 22, at 5 P.M. Further information can be obtained from Madeline in the Psychology Department office at (212) 854-8859.

A memorial meeting in honor of Fred Keller will also be held at the Association for Behavioral Analysis in San Francisco on May 28, 1996.

The University of New Hampshire is organizing a Keller archive, which consists of assorted correspondence and papers that he had presented at various meetings since about 1960. It is called "The Fred Keller Collection" and will be located in the Dimand Library, University of New Hampshire, in Durham, NH. Information on the collection is available on the World Wide Web.

The remarkable book, "Principles of Psychology," co-authored with W. N. Schoenfeld, has recently been re-issued by the B. F. Skinner Foundation. There is still nothing like it.

Fred's own full and lengthy autobiography will be published by Society for the Advancement of Behavior Analysis.

\section{A Farewell}

The day of the last lecture in that introductory course-so many years ago and still so fresh to me-Fred permitted himself one of his rare perorations:

The world is an awful place. People in it know much and accomplish much, but spread suffering among each other and seem unable to avoid this. They even know something of this fact, but that seems not to be enough. We need the kind of knowledge that will actually change how people do things, so that the amount of suffering might diminish. I believe that a science of behavior can make a contribution to that end.

As the clapping began, Fred Keller disappeared from the classroom. I knew where his office was, and after a few moments of the continued clapping with its object no longer present became difficult to bear. I ran up the flight of stairs and found him in his office. I said something about hoping to continue on in this field. He said, "You will find no end of challenges."

Years have passed, and now Fred Keller the man is gone. What he taught us, 


\section{FRED S. KELLER}

we know well. But how well is well enough? The challenges remain.

\section{REFERENCES}

Boring, E. G., Langfeld, H. S., and Weld, H. P. (1946). Foundations of psychology. New York: Wiley. Bryan, W. L. \& Harter, N. (1897). Studies in the physiology and psychology of the telegraphic language. Psychological Review, 4, 27-53. http://dx.doi.org/10.1037/h0073806

Bryan, W. L. \& Harter, N. (1897). Studies in the physiology and psychology of the telegraphic language: The acquisition of a hierarchy of habits.

Cook, D. A. (1972). Message type as a parameter of learning to receive International Morse Code. Ann Arbor, MI: University Microfilms, Document 72-78, 028.

Keller, F.S. (1968). Good-bye, teacher... Journal of Applied Behavior Analysis, 1, 79-89. http://dx.doi.org/10.1901/jaba.1968.1-79

Keller, F. S. (1943). Studies in International Morse Code: 1. A new method of teaching code reception. Journal of Applied Psychology, 27, 407-415. http://dx.doi.org/10.1037/h0055363

Keller, F. S. (1958). The phantom plateau. Address of the President at the Eastern Psychological Association. New York, April 1957. Journal of the Experimental Analysis of Behavior, 1, 1-14. http://dx.doi.org/10.1901/jeab.1958.1-1

Keller, F. S. (1977). Summers and sabbaticals: Selected papers on psychology and education. Champaign, IL: Research Press, Co.

Keller, F. S., Estes, K. W., \& Murphy, P. G. (1944). A comparison of training methods at two levels of code learning (Report No. 4329). Washington, D. C: U. S. Department of Commerce.

Keller, F. S. \& Schoenfeld, W. N. (1950). Principles of psychology: A systematic text in the science of behavior. New York: Appleton-Century-Crofts.

Keller, F. S. \& Sherman, J. G. (1964). PSI, the Keller Plan Handbook: Essays on a personalized system of instruction. Menlo Park, CA: W. A. Benjamin.

Munn, N. L. (1946). Psychology: Fundamentals of human adjustment. New York \& Boston: Houghton Mifflin Co.

Kurtz, A. K. (1959). Recent developments, practices, and research in the field of code learning. Technical Report No. 1, prepared under Contract Nonr 2519(00) between the Office of Naval Research and the Psychological Corporation.

West, D. J. (1955). Review of research on Morse Code learning. Training Aids Research Laboratory, Air Force Training and Personal Research Center. Air Research and Development Command, Chanute Air Force Base, IL.

Woodworm, R. S. \& Marquis, D. G. (1947). Psychology (5th Ed.). New York: Henry Holt.

Woodworm, R. S. (1938). Experimental psychology. New York: H. Holt \& Co. 